\title{
Epidemiology of Clostridium difficile-associated disease at University Hospital Basel including molecular characterisation of the isolates 2006-2007
}

\author{
L. Fenner • R. Frei • M. Gregory • M. Dangel • \\ A. Stranden • A. F. Widmer
}

Received: 21 January 2008/Accepted: 25 May 2008 /Published online: 17 June 2008

(C) Springer-Verlag 2008

\begin{abstract}
A prospective study was conducted during a oneyear period between 2006 and 2007 to describe the epidemiology of Clostridium difficile-associated disease (CDAD) at University Hospital Basel, Switzerland (UHBS) and to determine phenotypic and genotypic features of $C$. difficile strains isolated at the Microbiology Laboratory UHBS including strains from regional non-university hospitals. We prospectively identified $78 \mathrm{CDAD}$ cases at UHBS with an incidence of 2.65/1,000 hospitalised patients or $2.3 / 10,000$ patient-days. Sixteen patients $(20.5 \%)$ were infected with clindamycin-resistant strains of PCR-ribotype 027 during an outbreak at the geriatric hospital. Among 124 single-patient isolates, $28(22.6 \%)$ were resistant to moxifloxacin and 34 (27.4\%) were resistant to clindamycin, but all remained susceptible to metronidazole and vancomycin. Of 102 toxigenic isolates, 19 (18.7\%) had an 18-bp deletion in the $t c d C$ gene, eight (7.8\%) a 39-bp deletion, and one $(1.0 \%)$ a $54-b p$ deletion. Genes for binary toxin were present in 27 (21.8\%). PCR-ribotype 027 was associated with older age (median age 83.5 vs. 65.5 years, $p<0.0001$ ) and longer duration of hospitalisation before onset of disease (median 15.5 vs. 9 days, $p=0.014$ ) with a trend towards higher crude mortality, more severe disease, and previous use of macrolides compared to ribotype non-027.
\end{abstract}

\footnotetext{
L. Fenner $\cdot$ R. Frei

Microbiology Laboratory, University Hospital Basel,

Petersgraben 4,

4031 Basel, Switzerland

M. Gregory • M. Dangel • A. Stranden · A. F. Widmer $(\square)$ Division of Infectious Diseases and Hospital Epidemiology, University Hospital Basel,

Petersgraben 4,

4031 Basel, Switzerland

e-mail: awidmer@uhbs.ch
}

Overall, severe disease correlated with use of a nasogastric tube and surprisingly shorter duration of hospitalisation before onset of disease. Today, laboratory-based and epidemiological surveillance systems are required to monitor CDAD cases and emergence of new epidemic strains.

\section{Introduction}

Clostridium difficile is one of the most important nosocomial pathogens. It is the most frequent cause of antibioticassociated diarrhoea $[1,2]$. C. difficile-associated disease (CDAD) has become an increasing clinical problem in the hospital setting as well as in the community [3]. The spectrum of disease is wide-from asymptomatic colonization, mild or self-limiting diarrhoea to life-threatening pseudomembranous colitis [4]. Recently, a new virulent $C$. difficile strain characterised as toxinotype III, North American pulsed-field type 1, restriction-endonuclease analysis group type BI, and PCR-ribotype 027 has emerged worldwide causing outbreaks in North America and Europe $[4,5]$. CDAD due to this hypervirulent strain is associated with increased morbidity and mortality [6-8]. It has been suggested that increased virulence results from hyperproduction of toxins $\mathrm{A}$ and $\mathrm{B}$ as a result of deletions in the putative negative regulator gene $(t c d C)$ leading to truncated amino acid residues with insufficient function [9]. More severe disease and a higher case-fatality rate have also been associated with $C$. difficile strains producing actin-specific ADP-ribosyltransferase (binary toxin) $[6,10]$. Other toxinvariant strains such as toxin A-negative/toxin B-positive and toxin A-positive/toxin B-negative strains are also associated with disease or outbreaks [11, 12].

In this study, we aimed to determine phenotypic and genotypic features of $C$. difficile strains isolated at the 
Microbiology Laboratory of the University Hospital Basel, Switzerland during a one-year period between 2006 and 2007. Furthermore, we prospectively identified all CDAD cases including a first cluster of 16 CDAD patients with clindamycin-resistant $C$. difficile PCR-ribotype 027 at University Hospital Basel and the affiliated geriatric hospital in Basel (UHBS) [13] during the same study period. We analysed clinical and epidemiological patient data as well as the corresponding $C$. difficile isolates in order to compare strain characteristics with clinical presentation.

\section{Material and methods}

Microbiological analyses

All faecal specimens from patients suspected of having CDAD and submitted to the laboratory for $C$. difficile testing between June 2006 and July 2007 were included in the study. Specimens were sent by UHBS and surrounding hospitals. Samples were tested for toxin A/B using the enzyme-linked immunosorbent assay C.DIFF TOX A/B II (TechLab/Wampole, Blacksburg, VA, USA) according to manufacturer's instructions and simultaneously cultured as previously described [14]. DNA was extracted with LC MagnaPure systems (Roche Diagnostics, Rotkreuz, Switzerland). A single patient isolate was defined as an isolate per patient including repetitive isolates if at least four weeks apart. Genes for toxins A/B and binary toxin were detected by PCR [15]; the $t c d C$ genotype was determined by sequencing $[15,16]$. Ribotyping was performed by the methods of Stubbs et al. [17]. Antibiotic susceptibility to metronidazole, moxifloxacin, clindamycin, and vancomycin was determined by Etest (AB Biodisk, Solna, Sweden) and interpreted in accordance with the Clinical and Laboratory Standards Institute [18]. MICs $\geq 8 \mathrm{mg} / \mathrm{l}$ for moxifloxacin and MICs $\geq 8 \mathrm{mg} / \mathrm{l}$ for clindamycin were regarded as resistant; MICs $\leq 8 \mathrm{mg} / 1$ for metronidazole and MICs $\leq 2 \mathrm{mg} / 1$ for vancomycin were deemed susceptible.

Clinical data and definitions

The UHBS is a 680 -bed tertiary care centre with 27,000 admissions and 167,000 outpatients per year. In 2001, the UHBS initiated a surveillance system for $C$. difficile. Cases are classified as asymptomatic carrier, mild or severe CDAD. For the purpose of this study, additional data from cases were prospectively completed by full-chart review using a standardized case report form over 12 months. Data cleaning was performed by manually reviewing the charts by a board-certified infectious diseases specialist and by checking for outliers in the analyses. The following date were collected: demographic data (age, sex), duration of hospitalisation, hospital ward, symptoms of CDAD (diarrhoea defined as more than three episodes per day), fever, relevant laboratory results (C-reactive protein, white blood cell count, albumin), antibiotic therapy, comorbidity using the Charlson index [19], McCabe classification [20], and

Table 1 Phenotypic and genotypic features of 124 Clostridium difficile single-patient strains isolated during a one-year period at the Microbiology Laboratory, University Hospital Basel

\begin{tabular}{|c|c|c|c|}
\hline & $\begin{array}{l}\text { All }(n=124) \\
n(\%)\end{array}$ & $\begin{array}{l}\text { PCR-ribotype } 027(n=18) \\
n(\%)\end{array}$ & $\begin{array}{l}\text { PCR-ribotype non-027 }(n=106) \\
n(\%)\end{array}$ \\
\hline Moxifloxacin resistant & $28(22.6)$ & $18(100)$ & $10(9.4)$ \\
\hline Clindamycin resistant & $34(27.4)$ & $18(100)$ & $16(15.1)$ \\
\hline Both resistant & $21(16.9)$ & $18(100)$ & $3(2.8)$ \\
\hline \multicolumn{4}{|l|}{ Toxine $\mathrm{A} / \mathrm{B}$ profile } \\
\hline Tox $\mathrm{A}-/ \mathrm{B}-$ & $21(16.9)$ & 0 & $21(19.8)$ \\
\hline Tox $\mathrm{A}+/ \mathrm{B}-$ & $2(1.6)$ & 0 & $2(1.9)$ \\
\hline Tox $\mathrm{A}+/ \mathrm{B}+$ & $101(81.5)$ & $18(100)$ & $83(78.3)$ \\
\hline Binary toxin + & $27(21.8)$ & $18(100)$ & $9(8.5)$ \\
\hline tcdC genotype (n) & & tcdC-sc1 (18) & tcdC-A (8), tcdC-UHBS2 (1) \\
\hline \multicolumn{4}{|l|}{$t c d C$ genotype $(\mathrm{n}=102)$} \\
\hline Wildtype WT-1 & $7(6.9)$ & 0 & $7(8.3)$ \\
\hline Wildtype WT-2 & $3(2.9)$ & 0 & $3(3.6)$ \\
\hline Wildtype WT-3 & $4(3.9)$ & 0 & $4(4.8)$ \\
\hline Wildtype WT-4 & $60(58.8)$ & 0 & $60(71.4)$ \\
\hline tcdC-sc1 (18-bp deletion) & 18 (17.7) & $18(100)$ & 0 \\
\hline tcdC-A (39-bp deletion) & $8(7.8)$ & 0 & $8(9.5)$ \\
\hline tcdC-B (18-bp deletion) & $1(1.0)$ & 0 & $1(1.2)$ \\
\hline UHBS-2 (54-bp deletion) & $1(1.0)$ & 0 & $1(1.2)$ \\
\hline
\end{tabular}

$t c d C$ putative negative regulator gene, + presence, - absence 
underlying diseases according to the International Classification of Diseases (ICD, 10th edition). They were matched with the microbiological results obtained from $C$. difficile patient isolates during the same study period including cases with clindamycin-resistant $C$. difficile PCR-ribotype 027 from a cluster previously reported [13]. CDAD was defined by the presence of diarrhoea and a positive result for toxin $\mathrm{A} / \mathrm{B}$ or a patient suffering from diarrhoea, a positive $C$. difficile stool culture, a clinical diagnosis in the chart, plus a therapy with vancomycin or metronidazole $[21,22]$. A complicated clinical course was defined as admission to an intensive care unit, need for surgical intervention, or death. Recurrent CDAD was considered if a positive toxin or stool culture was detected within three months after first diagnosis; reinfection was defined when a new CDAD episode was diagnosed after three months during the same hospitalisation or during a new hospitalisation. A case of CDAD was classified as severe if one of the following complications occurred: paralytic ileus, toxic megacolon, severe dehydration, or severe sepsis. Cases were classified as moderate if at least three or as mild if less than three of the following symptoms were present: fever $>38.5^{\circ} \mathrm{C}$, severe diarrhoea, abdominal pain, and leukocytosis $\left(>10^{9} / 1\right)$.

\section{Statistical analyses}

SPSS statistical software version 14.0 (SPSS Inc., Chicago, IL, USA) was used for statistical analysis. Odds ratios (OR) of binary, categorical, or continuous variables were determined by logistic regression (univariate). Statistical significance of dichotomous variables was achieved by using $\chi^{2}$, Fisher's exact, or nonparametric tests when appropriate.

\section{Results}

\section{Analysis of strains}

The phenotypic and genotypic features of 124 singlepatient isolates are given in Table 1. A total of 98 isolates (79\%) were obtained from UHBS and $26(21 \%)$ from surrounding hospitals. Overall, 103 strains $(83.1 \%)$ were toxigenic (101 toxin A and B positive, two toxin A positive and $\mathrm{B}$ negative). PCR-ribotype 027 was detected in 18 isolates. The $t c d C$ gene was not detected in $1 / 103(1 \%)$ toxigenic isolates (strain was toxin $\mathrm{A}$ positive and $\mathrm{B}$ negative). Most frequent $t c d C$ genotypes were wild-types, tcdC-sc1, and tcdC-A (Table 1). Genotypes tcdC-WT1 to WT4 showed no deletions in their sequences and were therefore considered as wild-type (GeneBank accession no. EU075382, EU075378, EU075379, and EU075380). tcdC-A
Table 2 Clinical features of 78 patients with Clostridium difficileassociated disease (CDAD) at the University Hospital Basel, Switzerland

\begin{tabular}{|c|c|}
\hline Characteristic & $n(\%)$ \\
\hline \multicolumn{2}{|l|}{ Sex } \\
\hline Male & $38(48.7)$ \\
\hline \multicolumn{2}{|l|}{ Age, years } \\
\hline$\leq 50$ & $16(20.5)$ \\
\hline $51-65$ & $14(18.0)$ \\
\hline$>65$ & $48(61.5)$ \\
\hline \multicolumn{2}{|l|}{ Classification of disease } \\
\hline Mild & $49(62.8)$ \\
\hline Moderate & $22(28.2)$ \\
\hline Severe & $5(6.4)$ \\
\hline Complicated clinical course $^{\mathrm{a}}$ & $25(32.1)$ \\
\hline Death (within 30 days) & $7(9.0)$ \\
\hline \multicolumn{2}{|l|}{ Follow-up ${ }^{\mathrm{b}}$} \\
\hline Recurrence & $3(3.8)$ \\
\hline Reinfection & $2(2.6)$ \\
\hline \multicolumn{2}{|l|}{ Development of diarrhoea } \\
\hline Community-onset (prior or within 2 days) & $2(2.6)$ \\
\hline Hospital associated (between $2-14$ days) & $43(55.1)$ \\
\hline Hospital associated (after 14 days) & $32(42.3)$ \\
\hline \multicolumn{2}{|l|}{ Underlying disease } \\
\hline Rehabilitation & $20(25.6)$ \\
\hline Neoplasm & $12(15.4)$ \\
\hline Infectious disease & $11(14.1)$ \\
\hline Cardiovascular system disease & $6(7.7)$ \\
\hline Respiratory disease & $3(3.8)$ \\
\hline Others & $26(33.3)$ \\
\hline $\begin{array}{l}\text { Duration of hospitalisation before onset of diarrhoea, } \\
\text { days (median [IQR]) }\end{array}$ & $11.5(5-22)$ \\
\hline \multicolumn{2}{|l|}{ Previous use of antibiotics } \\
\hline Any antibiotic & $71(91.0)$ \\
\hline Penicillins + betalactamase inhibitor & $42(53.8)$ \\
\hline Cephalosporins & $12(15.4)$ \\
\hline Quinolones & $18(23.1)$ \\
\hline Macrolides & $4(5.1)$ \\
\hline Clindamycin & $1(1.3)$ \\
\hline Other & $18(23.1)$ \\
\hline Duration of antibiotic therapy, days (median [IQR]) & $8(6-12)$ \\
\hline Use of protone pump inhibitors & $47(60.3)$ \\
\hline \multicolumn{2}{|l|}{ Laboratory parameters at time of diagnosis } \\
\hline White blood cell count, $>10^{9} / 1$ & $41(52.6)$ \\
\hline Albuminaemia, $<35 \mathrm{~g} / 1$ & $60(76.9)$ \\
\hline C-reactive protein, $>40 \mathrm{mg} / 1$ & $49(62.8)$ \\
\hline Fever $>38.5^{\circ} \mathrm{C}$ & $24(30.8)$ \\
\hline \multicolumn{2}{|l|}{ McCabe score } \\
\hline No fatal disease & $54(69.2)$ \\
\hline Fatal disease in the following 5 years & $17(21.8)$ \\
\hline Fatal disease in the following 0.5 year & $7(9.0)$ \\
\hline Charlson index $($ mean $\pm \mathrm{SD})$ & $2.6( \pm 1.9)$ \\
\hline \multicolumn{2}{|l|}{ Predisposing factors } \\
\hline Previous surgery (1 month) & $26(33.3)$ \\
\hline Cancer & $12(15.4)$ \\
\hline Nasogastric tube & $12(15.4)$ \\
\hline Chemotherapy & $12(15.4)$ \\
\hline Immunosupression & $9(11.5)$ \\
\hline
\end{tabular}


Table 2 (continued)

\begin{tabular}{ll}
\hline Characteristic & $n(\%)$ \\
\hline Hospital ward & \\
Internal medicine & $33(42.3)$ \\
Surgical department & $10(12.8)$ \\
Intensive care unit & $7(9.0)$ \\
Geriatric & $24(30.8)$ \\
Others & $4(5.1)$ \\
\hline
\end{tabular}

$I Q R$ interquartile range, $S D$ standard deviation

${ }^{a}$ Defined as admission to an intensive care unit, surgical intervention, or death

${ }^{b}$ At least one or more than one recurrence or reinfection

(39-bp deletion), tcdC-B (18-bp deletion), and tcdC-sc1 (18-bp deletion plus single nucleotide deletion at position 117) correspond to genotypes previously described $[9,16]$ whereas the sequence of tcdC-UHBS2 with a 54-bp deletion is newly recognized (GeneBank accession no. EU075381). All strains with ribotype 027 were moxifloxacin resistant (MIC $>32 \mathrm{mg} / \mathrm{l}$, sensitivity $100 \%$ ), and the frequency of resistance to moxifloxacin among non-027 strains was $9.4 \%$ (specificity 90.6\%) (Table 1). Among toxigenic strains, $\mathrm{MIC}_{50}$ and $\mathrm{MIC}_{90}$ for metronidazole and vancomycin were
$0.064 \mathrm{mg} / 1$ and $0.25 \mathrm{mg} / 1,0.5 \mathrm{mg} / 1$ and $1.5 \mathrm{mg} / \mathrm{l}$, respectively, and therefore interpreted as susceptible.

Epidemiological data and patient characteristics

Among the microbiologically analysed single-patient isolates during the study period, 78 fulfilled the case definition of CDAD and complete data from chart review was available. Among these, ten CDAD cases were toxinnegative but suffered from diarrhoea, were $C$. difficile culture positive, and were treated for CDAD. In eight cases, the strain was not available for further microbiological analysis. Overall, incidence was 2.65 per 1,000 hospitalized patients and 2.3 per 10,000 patient-days. Among all CDAD cases, $61.5 \%$ were older than 65 years, $62.8 \%$ had a mild clinical course, crude mortality was $9 \%$, frequency of community-onset of CDAD was $2.6 \%$, and recurrence rate was $3.8 \%$ (Table 2). The median duration of hospitalisation before onset of diarrhoea was 11.5 days; $91 \%$ of patients had documented antibiotic therapy before disease onset and most common underlying disease/diagnosis was rehabilitation, neoplasm, and infectious disease. Only four $(5.1 \%)$ did not receive a specific treatment, but all of them were toxin-positive.

Table 3 Comparison of Clostridium difficile-associated disease (CDAD) patients infected with PCR-ribotype 027 versus non-027 strains

\begin{tabular}{|c|c|c|c|c|}
\hline \multicolumn{5}{|l|}{ PCR-ribotype } \\
\hline Variable & 027 strains $(n=16)$ & Non-027 strains $(n=44)$ & OR $(95 \% \mathrm{CI})$ & $p$ \\
\hline Age, years (median, IQR) & $82.5(78.5-91.5)$ & $65.5(53.5-77)$ & & $<0.0001$ \\
\hline Moderate to severe CDAD 7 & $7(43.8)$ & $15(34.1)$ & $1.4(0.43-4.52)$ & 0.57 \\
\hline Complicated clinical course $^{\mathrm{a}}(n, \%)$ & $4(25.0)$ & $17(38.6)$ & $0.53(0.15-1.89)$ & 0.33 \\
\hline Follow-up ${ }^{\mathrm{b}}$ & $4(25.0)$ & & & \\
\hline Recurrence & $1(6.2)$ & $2(4.6)$ & $1.41(0.12-16.67)$ & 0.79 \\
\hline Reinfection $(n, \%)$ & $1(6.2)$ & $1(2.3)$ & $2.86(0.17-47.62)$ & 0.45 \\
\hline Death (within 30 days) & $3(18.8)$ & $4(9.1)$ & $2.3(0.46-11.11)$ & 0.31 \\
\hline $\begin{array}{l}\text { Duration of hospitalisation before onset of diarrhoea } \\
\text { (median days, IQR) }\end{array}$ & $15.5(12.5-50.5)$ & $9(5-18)$ & & 0.014 \\
\hline Duration of antibiotic therapy, days (median, IQR) & $9.5(6.5-13)$ & $7.5(5-13)$ & & 0.3 \\
\hline Use of protone pump inhibitors $(n, \%)$ & $9(56.3)$ & $27(61.4)$ & $0.81(0.25-2.56)$ & 0.72 \\
\hline \multicolumn{5}{|l|}{ Previous use of antibiotics $(n, \%)$} \\
\hline Beta-lactam antibiotics & $12(75.0)$ & $31(70.5)$ & $1.26(0.34-4.63)$ & 0.73 \\
\hline Quinolones & $6(37.5)$ & $9(20.5)$ & $2.33(0.67-8.14)$ & 0.18 \\
\hline Macrolides & $3(18.8)$ & $1(2.3)$ & $9.92(0.95-103.70)$ & 0.054 \\
\hline \multicolumn{5}{|l|}{ Laboratory parameters at time of diagnosis (n, \%) } \\
\hline White blood cell count $>10^{9} / 1$ & $9(56.3)$ & $22(50.0)$ & $1.28(0.41-4.0)$ & 0.67 \\
\hline Albuminaemia $<35 \mathrm{~g} / 1$ & $10(62.5)$ & $34(77.3)$ & $0.49(0.14-1.69)$ & 0.26 \\
\hline C-reactive protein $>40 \mathrm{mg} / 18$ & $8(50.0)$ & $28(63.6)$ & $0.57(0.18-1.82)$ & 0.34 \\
\hline Toxin A/B positive directly from stool ${ }^{\mathrm{c}}(n, \%)$ & $9(56.3)$ & $23(52.3)$ & $1.18(0.37-3.70)$ & 0.79 \\
\hline
\end{tabular}

95\% CI 95\% confidence interval, IQR interquartile range

${ }^{a}$ Defined as admission to an intensive care unit, surgical intervention, or death

b At least one or more than one recurrence or reinfection

c All cases were toxin-positive either directly from stool or by toxigenic culture 
Clinical and laboratory features in patients infected with $C$. difficile PCR-ribotype 027 and non-027

Comparing 60 patients for whom PCR-ribotyping results were available, we found that patients infected with $C$. difficile ribotype 027 (16 patients, or $20.5 \%$ of total CDAD cases) were significantly older than non-027 patients (median age 82.5 vs. 65.5 years, $p<0.0001$, Table 3 ) and were hospitalised longer before onset of diarrhoea (median 15.5 vs. 9 days, $p=0.014)$. Although statistically not significant, there was a trend towards more cases of moderate to severe CDAD in the 027 group ( $43.8 \%$ vs. $34.1 \%, p=0.57)$, higher crude mortality ( $18.8 \%$ vs. $9.1 \%, p=0.31)$, longer duration of antibiotic therapy before CDAD (median 15.5 vs. 9.0 days, $p=0.31)$, as well as previous use of quinolones $(37.5 \%$ vs. $25.7 \%, p=0.18)$ and macrolides $(18.8 \%$ versus $2.3 \%, p=$ $0.054)$. Recurrence and reinfection rate was generally low (2.3-6.2\%). Toxin A/B was detected in only half of the patients directly in stool specimens and would have been missed if toxin assay was performed alone (Table 3), but repeated toxin testing from $C$. difficile cultures from specimens that were toxin-negative directly from stool considerably increased sensitivity. In the non-027 group, seven patients underwent chemotherapy compared to zero patients in the 027 group.

Disease severity according to strain and patient characteristics

Disease severity of CDAD according to strain and patients' characteristics is summarized in Table 4. For two patients, the severity of disease was not assessable. The univariate analysis showed that moderate to severe CDAD is statistically significant associated with use of a nasogastric tube and with a shorter hospital stay before onset of diarrhoea (Table 4). Toxin A/B positivity directly detected from stool (instead of positive only from culture isolate testing) was significantly associated with moderate to severe disease $(p=0.048)$. We did not observe an association between severity of disease and PCR-ribotype 027, $t c d C$ genotype, as well as presence of binary toxin $\mathrm{A} / \mathrm{B}$. There was a trend towards more frequent recurrences and reinfection in the more severe disease group; however, the sample size was too small to infer an association.

Table 4 Disease severity of Clostridium difficile-associated disease (CDAD) cases according to strain and patients' characteristics

\begin{tabular}{|c|c|c|c|c|c|}
\hline \multirow[t]{2}{*}{ Variable } & \multirow{2}{*}{$\begin{array}{l}\text { No. of patients with } \\
\text { available information }\end{array}$} & \multicolumn{2}{|c|}{ Disease severity of CDAD } & \multirow[t]{2}{*}{ OR $(95 \% \mathrm{CI})$} & \multirow[t]{2}{*}{$p$} \\
\hline & & Moderate to severe & Mild & & \\
\hline Age, years (median, IQR) & 76 & $70(55-83)$ & $73(53-85)$ & & 0.88 \\
\hline Gender $(n, \%)$ & 76 & & & & \\
\hline Male & & $14(51.9)$ & $23(46.9)$ & $1.22(0.48-3.13)$ & 0.68 \\
\hline \multicolumn{6}{|l|}{ Follow-up ${ }^{\mathrm{a}}$} \\
\hline Recurrence $(n, \%)$ & 76 & $2(7.4)$ & $1(2.0)$ & $3.85(0.33-50.0)$ & 0.25 \\
\hline Reinfection (n, \%) & 76 & $1(3.7)$ & $1(2.0)$ & $1.85(0.11-33.33)$ & 0.665 \\
\hline Death (within 30 days) $(n, \%)$ & & $4(14.8)$ & $3(6.1)$ & $2.63(0.55-12.5)$ & 0.22 \\
\hline \multicolumn{6}{|l|}{ Predisposing factors $(n, \%)$} \\
\hline Previous surgery (within 3 months) & 76 & $3(11.1)$ & $5(10.2)$ & $1.09(0.24-5.0)$ & 0.9 \\
\hline Cancer & 76 & $3(11.1)$ & $9(18.4)$ & $0.56(0.14-2.27)$ & 0.4 \\
\hline Nasogastric tube & 76 & $7(25.9)$ & $4(8.2)$ & $4(1.03-14.29)$ & 0.03 \\
\hline Chemotherapy & 76 & $1(3.7)$ & $11(22.4)$ & $0.13(0.02-1.09)$ & 0.06 \\
\hline \multicolumn{6}{|l|}{ Laboratory parameters at time of diagnosis $(n, \%)$} \\
\hline Albuminaemia $<35 \mathrm{~g} / 1$ & 67 & $23(95.8)$ & $35(81.4)$ & $5.26(0.62-50.0)$ & 0.09 \\
\hline C-reactive protein $>40 \mathrm{mg} / 1$ & 73 & $20(74.0)$ & $27(58.7)$ & $2.01(0.71-5.69)$ & 0.19 \\
\hline $\begin{array}{l}\text { Duration of hospitalisation before onset of } \\
\text { diarrhoea, days (median, IQR) }\end{array}$ & 76 & $8(4-13)$ & $15(8-26)$ & & 0.002 \\
\hline Duration of antibiotic therapy, days (median, IQR) & & $6(3-11)$ & $9(7-12)$ & & 0.08 \\
\hline PCR-ribotype $027(n, \%)$ & 58 & $7(31.8)$ & $9(25.0)$ & $1.4(0.43-4.52)$ & 0.57 \\
\hline Binary toxin positive $(n, \%)$ & 68 & $8(36.4)$ & $14(30.4)$ & $1.31(0.45-3.82)$ & 0.63 \\
\hline Toxin A/B positive directly from stool $(n, \%)$ & 60 & $17(70.8)$ & $16(44.4)$ & $3.13(1.02-9.09)$ & 0.048 \\
\hline tcdC genotype $(n, \%)$ & 58 & & & & \\
\hline tcdC-A (39-bp deletion) & & $1(4.5)$ & $4(11.1)$ & $0.43(0.05-4.0)$ & 0.45 \\
\hline tcdC wildtype (no deletion) & & $14(63.6)$ & $22(61.1)$ & $1.32(0.52-3.45)$ & 0.56 \\
\hline
\end{tabular}

95\% CI 95\% confidence interval, IQR interquartile range

${ }^{a}$ At least one or more than one recurrence or reinfection 


\section{Discussion}

Overall, the incidence of $2.65 \mathrm{CDAD} / 1,000$ hospitalized patients or 2.3/10,000 patient-days was comparable to a study out of the Netherlands in 2005 (0.1-4.6, median 1.6/1,000 patient admissions) [23] and from a recent European survey (0.13-7.1/10,000 patient-days) [6]. The incidence of CDAD remained stable at the University Hospital, but increased during an outbreak with $C$. difficile PCR-ribotype 027 in January 2007 at the affiliated geriatric hospital [13]. The slightly higher incidence compared to the Netherlands may be partly explained by the definitions used. The new guidelines such as those issued by the European Centre for Disease Prevention and Control (ECDC) define CDAD more stringently $[4,24]$ than what was used in our study. These new guidelines require the detection of toxin that was negative in ten $(13 \%)$ of our cases, but fulfilled the Centers for Disease Control and Prevention (CDC) surveillance definition [22].

CDAD cases were similar to those of other European countries regarding age, sex, and severity of disease [10, 23]. In contrast to these studies, community-onset CDAD was rare (only $2.6 \%$ ) in this study and the recurrence rate was lower.

Among all C. difficile strains isolated at the Microbiology Laboratory during the study period, rates of resistance to moxifloxacin and clindamycin were overall rather low, but in the range of a recent European survey [6]. Moxifloxacin resistance was highly associated with the presence of PCRribotype 027; however, these strains were isolated from an outbreak, potentially biasing the strength of this association.

Comparing CDAD due to PCR-ribotype 027 with non 027 , ribotype 027 was significantly associated with older age and longer duration of hospital stay before onset of disease. Although a trend was seen towards higher crude mortality, a more severe clinical course, previous use of macrolides, and a longer duration of antibiotic therapy in the 027 patient group, these findings did not reach a statistically significant level, possibly due to small sample size. However, results from previous reports support the observed trends $[6,7]$. In contrast to the latter studies, our 027 strains were all clindamycin-resistant. It is noteworthy that previous use of macrolides was more strongly associated with PCR-ribotype 027 than use of quinolones, but both were statistically not significant.

Severe to moderate disease correlated with use of a nasogastric tube and shorter duration of hospitalisation before onset of diarrhoea. Strikingly, the clinical course of CDAD in patients under chemotherapy was mild; these patients were predominantly cared for in a special haematological unit where immediate treatment with metronidazole after onset of any kind of diarrhoea is standard of care. Disease severity was not linked to the presence of $t c d C$ deletions or binary toxin in contrast to previous findings [6, 10]. However, the percentage of binary-toxin positive strains among CDAD cases was quite high (37\%) compared to the average among all strains isolated at the laboratory (22\%) from patients with and without clinical symptoms. Patients with toxin-positive stool specimens experienced a more severe disease (compared to patients with toxinnegative faeces but with a toxigenic culture result), possibly due to higher stool toxin levels. The disease is mediated by toxins $\mathrm{A}$ and $\mathrm{B}$, but toxin levels and bacterial counts in stool are probably affected by many factors and there seems to be no correlation between severity of disease and faecal toxin level $[4,25]$. Surprisingly, two strains were toxin A positive but toxin B negative by the PCR method we used. They were isolated from two patients without CDAD diagnosis. This is a rare observation that requires confirmation [11].

A limitation of our study is the relatively small number of total CDAD cases and the small subgroup of patients infected with ribotype 027 during the 12 -month period. However, all consecutive cases were included, clinical data were complete and comprehensive, and isolates were genotypically and phenotypically well characterised. The follow-up period varied but was at least one month, and we cannot rule out that recurrences were treated in the outpatient setting. But seriously ill patients requiring hospitalization are unlikely to go elsewhere since the University Hospital is the only tertiary care hospital in the region.

Based on our study, we propose the introduction of laboratory-based and epidemiological surveillance systems, at least periodically and in populations at high risk. Susceptibility testing of culture isolates for moxifloxacin may serve as a basic screening marker for the epidemic ribotype 027 strains. Incidence and clinical presentation of CDAD cases must be monitored combined with molecular characterisation of strains to detect emergence of new epidemic strains.

Acknowledgements We are indebted to Dr Ed J. Kuijper for helpful discussion and for confirmation of PCR-ribotype 027. We thank the infection control team and the microbiology laboratory team at University Hospital Basel for excellent assistance.

\section{References}

1. Asha NJ, Tompkins D, Wilcox MH (2006) Comparative analysis of prevalence, risk factors, and molecular epidemiology of antibioticassociated diarrhea due to Clostridium difficile, Clostridium perfringens, and Staphylococcus aureus. J Clin Microbiol 44:2785-2791. DOI 10.1128/JCM.00165-06

2. Guerrant RL, Van GT, Steiner TS, Thielman NM, Slutsker L, Tauxe RV, et al (2001) Practice guidelines for the management of infectious diarrhea. Clin Infect Dis 32:331-351. DOI 10.1086/ 318514

3. CDC (2005) Severe Clostridium difficile-associated disease in populations previously at low risk-four states, 2005. MMWR Morb Mortal Wkly Rep 54:1201-1205 
4. Kuijper EJ, Coignard B, Tull P (2006) Emergence of Clostridium difficile-associated disease in North America and Europe. Clin Microbiol Infect 12(suppl 6):2-18. DOI 10.1111/j.14690691.2006.01580.x

5. McDonald LC, Killgore GE, Thompson A, Owens RC Jr, Kazakova SV, Sambol SP, et al (2005) An epidemic, toxin genevariant strain of Clostridium difficile. N Engl J Med 353:24332441. DOI 10.1056/NEJMoa051590

6. Barbut F, Mastrantonio P, Delmee M, Brazier J, Kuijper E, Poxton I (2007) Prospective study of Clostridium difficile infections in Europe with phenotypic and genotypic characterisation of the isolates. Clin Microbiol Infect 13:1048-1057. DOI 10.1111/ j.1469-0691.2007.01824.x

7. Goorhuis A, van der Kooi T, Vaessen N, Dekker FW, van den Berq R, Harmanus C, van den Hof S, Notermans DW, Kuijper EJ (2007) Spread and epidemiology of Clostridium difficile polymerase chain reaction ribotype 027/toxinotype III in The Netherlands. Clin Infect Dis 45:695-703. DOI 10.1086/520984

8. Hubert B, Loo VG, Bourgault AM, Poirier L, Dascal A, Fortin E, et al (2007) A portrait of the geographic dissemination of the Clostridium difficile North American pulsed-field type 1 strain and the epidemiology of $C$. difficile-associated disease in Quebec. Clin Infect Dis 44:238-244. DOI 10.1086/510391

9. Curry SR, Marsh JW, Muto CA, O'leary MM, Pasculle AW, Harrison LH (2007) $t c d C$ genotypes associated with severe TcdC truncation in an epidemic clone and other strains of Clostridium difficile. J Clin Microbiol 45:215-221

10. Barbut F, Gariazzo B, Bonne L, Lalande V, Burghoffer B, Luiuz R, et al (2007) Clinical features of Clostridium difficile-associated infections and molecular characterization of strains: results of a retrospective study, 2000-2004. Infect Control Hosp Epidemiol 28:131-139. DOI 10.1086/511794

11. Cohen SH, Tang YJ, Hansen B, Silva J Jr (1998) Isolation of a toxin B-deficient mutant strain of Clostridium difficile in a case of recurrent $C$. difficile-associated diarrhea. Clin Infect Dis 26:410412

12. Van den Berg RJ, Claas EC, Oyib DH, Klaassen CH, Dijkshoorn L, Brazier JS, et al (2004) Characterization of toxin A-negative, toxin B-positive Clostridium difficile isolates from outbreaks in different countries by amplified fragment length polymorphism and PCR ribotyping. J Clin Microbiol 42:1035-1041. DOI 10.1128/ JCM.42.3.1035-1041.2004

13. Fenner L, Widmer AF, Stranden A, Conzelmann M, Goorhuis A, Harmanus C, et al (2008) First cluster of clindamycin-resistant Clostridium difficile PCR ribotype 027 in Switzerland. Clin Microbiol Infect 14:514-515. DOI 10.1111/j.1469-0691.2008. 01989.x
14. Fenner L, Widmer AF, Goy G, Rudin S, Frei R (2007) Rapid and reliable diagnostic algorithm for detection of Clostridium difficile. J Clin Microbiol 46:328-330. DOI 10.1128/JCM.01503-07

15. Persson S, Torpdahl M, Olsen KEP (2007) Novel multiplex-PCR method for detection of Clostridium difficile toxin $\mathrm{A}(\mathrm{tcd} A)$ and toxin $\mathrm{B}(t c d B)$ and the binary toxin $(c d t A / c d t B)$ genes applied on a Danish cohort. Presented at ECCMID, Nice, France, 2006

16. Spigaglia P, Mastrantonio P (2002) Molecular analysis of the pathogenicity locus and polymorphism in the putative negative regulator of toxin production $(T c d C)$ among Clostridium difficile clinical isolates. J Clin Microbiol 40:3470-3475. DOI 10.1128/ JCM.40.9.3470-3475.2002

17. Stubbs SL, Brazier JS, O'Neill GL, Duerden BI (1999) PCR targeted to the 16S-23S rRNA gene intergenic spacer region of Clostridium difficile and construction of a library consisting of 116 different PCR ribotypes. J Clin Microbiol 37:461-463

18. Clinical and Laboratory Standards Institute (2007) Methods for antimicrobial susceptibility testing of anaerobic bacteria: approved standard M11-A7, 7th ed. Wayne, PA, USA

19. Charlson ME, Pompei P, Ales KL, MacKenzie CR (1987) A new method of classifying prognostic comorbidity in longitudinal studies: development and validation. J Chronic Dis 40:373-383. DOI 10.1016/0021-9681(87)90171-8

20. McCabe WR, Jackson GG (1962) Gram-negative bacteremia. II. Clinical, laboratory and therapeutic observations. Arch Intern Med 127:856-869

21. Gerding DN, Johnson S, Peterson LR, Mulligan ME, Silva J Jr (1995) Clostridium difficile-associated diarrhea and colitis. Infect Control Hosp Epidemiol 16:459-477

22. Archibald LK, Banerjee SN, Jarvis WR (2004) Secular trends in hospital-acquired Clostridium difficile disease in the United States, 1987-2001. J Infect Dis 189:1585-1589. DOI 10.1086/383045

23. Paltansing S, van den Berg RJ, Guseinova RA, Visser CE, van der Vorm ER, Kuijper EJ (2007) Characteristics and incidence of Clostridium difficile-associated disease in The Netherlands, 2005. Clin Microbiol Infect 13:1058-1064. DOI 10.1111/j.14690691.2007.01793.x

24. McDonald LC, Coignard B, Dubberke E, Song X, Horan T, Kutty PK (2007) Recommendations for surveillance of Clostridium difficile-associated disease. Infect Control Hosp Epidemiol 28:140-145. DOI 10.1086/511798

25. Akerlund T, Svenungsson B, Lagergren A, Burman LG (2006) Correlation of disease severity with fecal toxin levels in patients with Clostridium difficile-associated diarrhea and distribution of PCR ribotypes and toxin yields in vitro of corresponding isolates. J Clin Microbiol 44:353-358. DOI 10.1128/JCM.44.2.353358.2006 